\title{
Halpern-Mann's iterations for Bregman strongly nonexpansive mappings in reflexive Banach spaces with applications
}

\author{
Jin-hua Zhu' and Shih-sen Chang ${ }^{2 *}$
}

${ }^{*}$ Correspondence:

changss@yahoo.cn

${ }^{2}$ College of Statistics and

Mathematics, Yunnan University of

Finance and Economics, Kunming,

Yunnan 650221, China

Full list of author information is

available at the end of the article

\begin{abstract}
We investigate strong convergence for Bregman strongly nonexpansive mappings by modifying Halpern and Mann's iterations in the framework of a reflexive Banach space. As applications, we apply our main result to problems of finding zeros of maximal monotone operators and equilibrium problems in reflexive Banach spaces.
\end{abstract}

MSC: 47H05; 47H09; 47J25

Keywords: Bregman strongly nonexpansive mapping; Bregman projection; Legendre function; totally convex function; Halpern's iteration; Mann's iteration

\section{Introduction}

Throughout this paper, we denote by $\mathbb{N}$ and $\mathbb{R}$ the sets of positive integers and real numbers, respectively. Let $E$ be a real reflexive Banach space, and let $C$ be a nonempty, closed and convex subset of $E$. Let $T: C \rightarrow C$ be a nonlinear mapping. The fixed point set of $T$ is denoted by $F(T)$, that is, $F(T)=\{x \in C: x=T x\}$. A mapping $T$ is said to be nonexpansive if

$$
\|T x-T y\| \leq\|x-y\|
$$

for all $x, y \in C$.

Many problems in nonlinear analysis can be reformulated as a problem of finding a fixed point of a nonexpansive mapping. In 1953, Mann [1] introduced the following iterative sequence $\left\{x_{n}\right\}$ which is defined by

$$
x_{n+1}=\alpha_{n} x_{n}+\left(1-\alpha_{n}\right) T x_{n},
$$

where the initial guess $x_{1} \in C$ is arbitrary and $\left\{\alpha_{n}\right\}$ is a real sequence in $[0,1]$. It is known that under appropriate settings, the sequence $\left\{x_{n}\right\}$ converges weakly to a fixed point of $T$. However, even in a Hilbert space, Mann's iteration may fail to converge strongly; for example, see [2].

Some attempts to construct an iteration method guaranteeing the strong convergence have been made. For example, Halpern [3] proposed the following so-called Halpern iteration:

$$
x_{n+1}=\alpha_{n} u+\left(1-\alpha_{n}\right) T x_{n},
$$

where $u, x_{1} \in C$ are arbitrary and $\left\{\alpha_{n}\right\}$ is a real sequence in $[0,1]$. 
Because of a simple construction, Halpern's iteration is widely used to approximate a solution of fixed points for nonexpansive mappings and other classes of nonlinear mappings by mathematicians in different styles [4-12].

The purpose of this work is to consider strong convergence results for Bregman strongly nonexpansive mappings in reflexive Banach spaces by modifying Halpern and Mann's iterations. We note that there are many examples which are Bregman strongly nonexpansive such as the Bregman projection, the resolvents of maximal monotone operators, the resolvents of equilibrium problems, the resolvents of variational inequality problems and others (see, for example, [13-16]). Finally, we give some applications concerning the problems of finding zeros of maximal monotone operators and equilibrium problems.

\section{Preliminaries and lemmas}

In the sequel, we begin by recalling some preliminaries and lemmas which will be used in the proof.

Let $E$ be a real reflexive Banach space with the norm $\|\cdot\|$, and let $E^{*}$ be the dual space of $E$. Throughout this paper, $f: E \rightarrow(-\infty,+\infty]$ is a proper, lower semi-continuous and convex function. We denote by $\operatorname{dom} f$ the domain of $f$, that is, the set $\{x \in E: f(x)<+\infty\}$.

Let $x \in \operatorname{int} \operatorname{dom} f$. The subdifferential of $f$ at $x$ is the convex set defined by

$$
\partial f(x)=\left\{x^{\prime \prime} \in E^{*}: f(x)+\left\langle x^{*}, y-x\right\rangle \leq f(y), \forall y \in E\right\},
$$

where the Fenchel conjugate of $f$ is the function $f^{*}: E^{*} \rightarrow(-\infty,+\infty]$ defined by

$$
f^{*}\left(x^{*}\right)=\sup \left\{\left\langle x^{*}, x\right\rangle-f(x): x \in E\right\} .
$$

We know that the following Young-Fenchel inequality holds:

$$
\left\langle x^{*}, x\right\rangle \leq f(x)+f^{*}\left(x^{*}\right), \quad \forall x \in E, x^{*} \in E^{*} .
$$

Furthermore, the equality holds if $x^{*} \in \partial f(x)$ (see also [17, Theorem 23.5]).

The set $l e v_{\leq}^{f}(r)=\{x \in E: f(x) \leq r\}$ for some $r \in \mathbb{R}$ is called a sublevel of $f$.

A function $f$ on $E$ is coercive [18] if the sublevel set of $f$ is bounded; equivalently,

$$
\lim _{\|x\| \rightarrow+\infty} f(x)=+\infty
$$

A function $f$ on $E$ is said to be strongly coercive [19] if

$$
\lim _{\|x\| \rightarrow+\infty} \frac{f(x)}{\|x\|}=+\infty
$$

For any $x \in \operatorname{int} \operatorname{dom} f$ and $y \in E$, the right-hand derivative of $f$ at $x$ in the direction $y$ is defined by

$$
f^{\circ}(x, y):=\lim _{t \rightarrow 0^{+}} \frac{f(x+t y)-f(x)}{t} .
$$

The function $f$ is said to be Gâteaux differentiable at $x$ if $\lim _{t \rightarrow 0^{+}} \frac{f(x+t y)-f(x)}{t}$ exists for any $y$. In this case, $f^{\circ}(x, y)$ coincides with $\nabla f(x)$, the value of the gradient $\nabla f$ of $f$ at $x$. 
The function $f$ is said to be Gâteaux differentiable if it is Gâteaux differentiable for any $x \in \operatorname{int} \operatorname{dom} f$. The function $f$ is said to be Fréchet differentiable at $x$ if this limit is attained uniformly in $\|y\|=1$. Finally, $f$ is said to be uniformly Fréchet differentiable on a subset $C$ of $E$ if the limit is attained uniformly for $x \in C$ and $\|y\|=1$. It is known that if $f$ is Gâteaux differentiable (resp. Fréchet differentiable) on int $\operatorname{dom} f$, then $f$ is continuous and its Gâteaux derivative $\nabla f$ is norm-to-weak" continuous (resp. continuous) on int $\operatorname{dom} f$ (see also [20, 21]). We will need the following result.

Lemma 2.1 [22] Iff $: E \rightarrow \mathbb{R}$ is uniformly Fréchet differentiable and bounded on bounded subsets of $E$, then $\nabla f$ is uniformly continuous on bounded subsets of $E$ from the strong topology of $E$ to the strong topology of $E^{*}$.

Definition 2.2 [23] The function $f$ is said to be:

(i) Essentially smooth if $\partial f$ is both locally bounded and single-valued on its domain.

(ii) Essentially strictly convex if $(\partial f)^{-1}$ is locally bounded on its domain and $f$ is strictly convex on every convex subset of dom $\partial f$.

(iii) Legendre if it is both essentially smooth and essentially strictly convex.

Remark 2.3 Let $E$ be a reflexive Banach space. Then we have

(i) $f$ is essentially smooth if and only if $f^{*}$ is essentially strictly convex (see [23, Theorem 5.4]).

(ii) $(\partial f)^{-1}=\partial f^{\prime \prime}($ see $[21])$.

(iii) $f$ is Legendre if and only if $f^{*}$ is Legendre (see [23, Corollary 5.5]).

(iv) If $f$ is Legendre, then $\nabla f$ is a bijection satisfying $\nabla f=\left(\nabla f^{*}\right)^{-1}$, $\operatorname{ran} \nabla f=\operatorname{dom} \nabla f^{*}=\operatorname{int} \operatorname{dom} f^{*}$ and $\operatorname{ran} \nabla f^{*}=\operatorname{dom} \nabla f=\operatorname{int} \operatorname{dom} f$ (see [23, Theorem 5.10]).

Examples of Legendre functions were given in [23, 24]. One important and interesting Legendre function is $\frac{1}{p}\|\cdot\|^{p}(1<p<\infty)$ when $E$ is a smooth and strictly convex Banach space. In this case the gradient $\nabla f$ of $f$ is coincident with the generalized duality mapping of $E$, i.e., $\nabla f=J_{p}(1<p<\infty)$. In particular, $\nabla f=I$ the identity mapping in Hilbert spaces. In the rest of this paper, we always assume that $f: E \rightarrow(-\infty,+\infty]$ is Legendre.

Let $f: E \rightarrow(-\infty,+\infty]$ be a convex and Gâteaux differentiable function. The function $D_{f}: \operatorname{dom} f \times \operatorname{int} \operatorname{dom} f \rightarrow[0,+\infty)$ defined as follows:

$$
D_{f}(y, x):=f(y)-f(x)-\langle\nabla f(x), y-x\rangle
$$

is called the Bregman distance with respect to $f$ [25].

Recall that the Bregman projection [26] of $x \in \operatorname{int} \operatorname{dom} f$ onto the nonempty closed and convex set $C \subset \operatorname{dom} f$ is the necessarily unique vector $P_{C}^{f}(x) \in C$ satisfying

$$
D_{f}\left(P_{C}^{f}(x), x\right)=\inf \left\{D_{f}(y, x): y \in C\right\} .
$$

Concerning the Bregman projection, the following are well known.

Lemma 2.4 [27] Let $C$ be a nonempty, closed and convex subset of a reflexive Banach space E. Let $f: E \rightarrow \mathbb{R}$ be a Gâteaux differentiable and totally convex function, and let $x \in E$. Then 
(a) $z=P_{C}^{f}(x)$ if and only if $\langle\nabla f(x)-\nabla f(z), y-z\rangle \leq 0, \forall y \in C$.

(b)

$$
D_{f}\left(y, P_{C}^{f}(x)\right)+D_{f}\left(P_{C}^{f}(x), x\right) \leq D_{f}(y, x), \quad \forall x \in E, y \in C
$$

Let $f: E \rightarrow(-\infty,+\infty]$ be a convex and Gâteaux differentiable function. The modulus of total convexity of $f$ at $x \in \operatorname{int} \operatorname{dom} f$ is the function $v_{f}(x, \cdot):[0,+\infty) \rightarrow[0,+\infty]$ defined by

$$
\nu_{f}(x, t):=\inf \left\{D_{f}(y, x): y \in \operatorname{dom} f,\|y-x\|=t\right\} .
$$

The function $f$ is called totally convex at $x$ if $v_{f}(x, t)>0$ whenever $t>0$. The function $f$ is called totally convex if it is totally convex at any point $x \in \operatorname{int} \operatorname{dom} f$ and is said to be totally convex on bounded sets if $v_{f}(B, t)>0$ for any nonempty bounded subset $B$ of $E$ and $t>0$, where the modulus of total convexity of the function $f$ on the set $B$ is the function $v_{f}: \operatorname{int} \operatorname{dom} f \times[0,+\infty) \rightarrow[0,+\infty]$ defined by

$$
v_{f}(B, t):=\inf \left\{v_{f}(x, t): x \in B \cap \operatorname{dom} f\right\} .
$$

We know that $f$ is totally convex on bounded sets if and only if $f$ is uniformly convex on bounded sets (see [27, Theorem 2.10]).

The next lemma turns out to be very useful in the proof of our main results.

Proposition 2.5 [28] If $x \in \operatorname{int} \operatorname{dom} f$, then the following statements are equivalent.

(i) The function $f$ is totally convex at $x$.

(ii) For any sequence $\left\{y_{n}\right\} \subset \operatorname{dom} f$,

$$
\lim _{n \rightarrow+\infty} D_{f}\left(y_{n}, x\right)=0 \Rightarrow \lim _{n \rightarrow+\infty}\left\|y_{n}-x\right\|=0 .
$$

Recall that the function $f$ is called sequentially consistent [27] if for any two sequences $\left\{x_{n}\right\}$ and $\left\{y_{n}\right\}$ in $E$ such that the first one is bounded,

$$
\lim _{n \rightarrow+\infty} D_{f}\left(y_{n}, x_{n}\right)=0 \quad \Rightarrow \quad \lim _{n \rightarrow+\infty}\left\|y_{n}-x_{n}\right\|=0
$$

Lemma 2.6 [29] The function $f$ is totally convex on bounded sets if and only if the function $f$ is sequentially consistent.

Let $C$ be a convex subset of int $\operatorname{dom} f$, and let $T$ be a self-mapping of $C$. A point $p \in C$ is called an asymptotic fixed point of $T$ (see $[30,31]$ ) if $C$ contains a sequence $\left\{x_{n}\right\}$ which converges weakly to $p$ such that $\lim _{n \rightarrow \infty}\left\|x_{n}-T x_{n}\right\|=0$. We denote by $\hat{F}(T)$ the set of asymptotic fixed points of $T$.

Definition 2.7 A mapping $T$ with a nonempty asymptotic fixed point set is said to be:

(i) Bregman strongly nonexpansive (see $[15,32]$ ) with respect to a nonempty $\hat{F}(T)$ if

$$
D_{f}(p, T x) \leq D_{f}(p, x), \quad \forall x \in C, p \in \hat{F}(T)
$$


and if whenever $\left\{x_{n}\right\} \subset C$ is bounded, $p \in \hat{F}(T)$ and

$$
\lim _{n \rightarrow \infty}\left(D_{f}\left(p, x_{n}\right)-D_{f}\left(p, T x_{n}\right)\right)=0
$$

it follows that

$$
\lim _{n \rightarrow \infty} D_{f}\left(x_{n}, T x_{n}\right)=0
$$

(ii) Bregman firmly nonexpansive $[13,16,33]$ if, for all $x, y \in C$,

$$
\langle\nabla f(T x)-\nabla f(T y), T x-T y\rangle \leq\langle\nabla f(x)-\nabla f(y), T x-T y\rangle
$$

or, equivalently,

$$
D_{f}(T x, T y)+D_{f}(T y, T x)+D_{f}(T x, x)+D_{f}(T y, y) \leq D_{f}(T x, y)+D_{f}(T y, x) .
$$

The existence and approximation of Bregman firmly nonexpansive mappings was studied in [16]. It is also known that if $T$ is Bregman firmly nonexpansive and $f$ is a Legendre function which is bounded, uniformly Fréchet differentiable and totally convex on bounded subsets of $E$, then $F(T)=\hat{F}(T)$ and $F(T)$ is closed and convex (see [16]). It also follows that every Bregman firmly nonexpansive mapping is Bregman strongly nonexpansive with respect to $F(T)=\hat{F}(T)$.

Let $f: E \rightarrow \mathbb{R}$ be a convex, Legendre and Gâteaux differentiable function. Following [34] and [25], we make use of the function $V_{f}: E \times E^{*} \rightarrow[0,+\infty)$ associated with $f$, which is defined by

$$
V_{f}\left(x, x^{*}\right)=f(x)-\left\langle x^{*}, x\right\rangle+f^{*}\left(x^{*}\right)
$$

for all $x \in E, x^{*} \in E^{*}$. Then $V_{f}$ is nonnegative and $V_{f}\left(x, x^{*}\right)=D_{f}\left(x, \nabla f^{\prime \prime}\left(x^{*}\right)\right)$ for all $x \in E$ and $x^{\prime \prime} \in E^{*}$. We know the following lemma (see [35]).

Lemma 2.8 Let $E$ be a reflexive Banach space, let $f: E \rightarrow \mathbb{R}$ be a convex, Legendre and Gâteaux differentiable function, and let $V_{f}$ be as in (2.3). Then

$$
V_{f}\left(x, x^{\prime \prime}\right)+\left\langle y^{\prime \prime}, \nabla f^{\prime \prime}\left(x^{\prime \prime}\right)-x\right\rangle \leq V_{f}\left(x, x^{\prime \prime}+y^{\prime \prime}\right)
$$

for all $x \in E$ and $x^{*}, y^{*} \in E^{*}$.

Let $E$ be a real reflexive Banach space, let $f: E \rightarrow(-\infty,+\infty$ ] be a proper lower semicontinuous function, then $f^{*}: E^{*} \rightarrow(-\infty,+\infty]$ is a proper weak" lower semi-continuous and convex function (see [36]). Hence $V_{f}$ is convex in the second variable. Thus, for all $z \in E$, we have

$$
D_{f}\left(z, \nabla f^{*}\left(\sum_{i=1}^{N} t_{i} \nabla f\left(x_{i}\right)\right)\right) \leq \sum_{i=1}^{N} t_{i} D_{f}\left(z, x_{i}\right),
$$

where $\left\{x_{i}\right\}_{i=1}^{N} \subset E$ and $\left\{t_{i}\right\}_{i=1}^{N} \subset(0,1)$ with $\sum_{i=1}^{N} t_{i}=1$. 
The following results are of fundamental importance for the techniques of analysis used in this paper.

Lemma 2.9 [37] Assume that $\left\{\alpha_{n}\right\}$ is a sequence of nonnegative real numbers such that

$$
\alpha_{n+1} \leq\left(1-\gamma_{n}\right) \alpha_{n}+\gamma_{n} \delta_{n}, \quad \forall n \in N
$$

where $\left\{\gamma_{n}\right\}$ is a sequence in $(0,1)$ and $\left\{\delta_{n}\right\}$ is a sequence such that

(a) $\lim _{n \rightarrow \infty} \gamma_{n}=0, \sum_{n=1}^{\infty} \gamma_{n}=\infty$;

(b) $\lim \sup _{n \rightarrow \infty} \delta_{n} \leq 0$.

Then $\lim _{n \rightarrow \infty} \alpha_{n}=0$.

Lemma 2.10 [38] Let $\left\{\alpha_{n}\right\}$ be a sequence of real numbers such that there exists a subsequence $\left\{n_{i}\right\}$ of $\{n\}$ such that $\alpha_{n_{i}}<\alpha_{n_{i}+1}$ for all $i \in \mathbb{N}$. Then there exists a nondecreasing sequence $\left\{m_{k}\right\} \subset \mathbb{N}$ such that $m_{k} \rightarrow \infty$, and the following properties are satisfied for all (sufficiently large) numbers $k \in \mathbb{N}$ :

$$
\alpha_{m_{k}} \leq \alpha_{m_{k}+1} \text { and } \quad \alpha_{k} \leq \alpha_{m_{k}+1}
$$

In fact, $m_{k}=\max \left\{j \leq k: \alpha_{j}<\alpha_{j+1}\right\}$.

\section{Main results}

In this section, we modify Halpern and Mann's iterations for finding a fixed point of a Bregman strongly nonexpansive mapping in a real reflexive Banach space.

Lemma 3.1 [39] Let $C$ be a nonempty, closed and convex subset of a real reflexive Banach space $E$. Let $f: E \rightarrow \mathbb{R}$ be a Gâteaux differentiable and totally convex function, and let $T: C \rightarrow C$ be a mapping such that $\hat{F}(T)=F(T)$ is nonempty, closed and convex. Suppose that $u \in C$ and $\left\{x_{n}\right\}$ is a bounded sequence in $C$ such that $\lim _{n \rightarrow \infty}\left\|x_{n}-T x_{n}\right\|=0$. Then

$$
\limsup _{n \rightarrow \infty}\left\langle\nabla f(u)-\nabla f(p), x_{n}-p\right\rangle \leq 0,
$$

where $p=P_{F(T)}^{f}(u)$ and $P_{F(T)}^{f}$ is the Bregman projection of $C$ onto $F(T)$.

Theorem 3.2 Let $E$ be a real reflexive Banach space $E$, and let $f: E \rightarrow \mathbb{R}$ be a strongly coercive Legendre function which is bounded, uniformly Fréchet differentiable and totally convex on bounded subsets of $E$. Let $T$ be a Bregman strongly nonexpansive mapping on $E$ such that $F(T)=\hat{F}(T) \neq \emptyset$. Suppose that $u \in E$ and define the sequence $\left\{x_{n}\right\}$ as follows: $x_{1} \in E$ and

$$
x_{n+1}=\nabla f^{\prime \prime}\left(\alpha_{n} \nabla f(u)+\left(1-\alpha_{n}\right)\left(\beta_{n} \nabla f\left(x_{n}\right)+\left(1-\beta_{n}\right) \nabla f\left(T x_{n}\right)\right)\right), \quad \forall n \geq 1,
$$

where $\left\{\alpha_{n}\right\}$ and $\left\{\beta_{n}\right\}$ are sequences in $(0,1)$ satisfying

(C1) $\lim _{n \rightarrow \infty} \alpha_{n}=0$;

(C2) $\sum_{n=1}^{\infty} \alpha_{n}=\infty$;

(C3) $0<\liminf _{n \rightarrow \infty} \beta_{n} \leq \limsup \sup _{n \rightarrow \infty} \beta_{n}<1$. 
Then $\left\{x_{n}\right\}$ converges strongly to $P_{F(T)}^{f}(u)$, where $P_{F(T)}^{f}$ is the Bregman projection of E onto $F(T)$.

Proof We note, by Reich and Sabach [16], that $F(T)$ is closed and convex. Let $p=P_{F(T)}^{f}(u) \in$ $F(T)=\hat{F}(T)$ and $y_{n}=\nabla f^{\prime \prime}\left(\beta_{n} \nabla f\left(x_{n}\right)+\left(1-\beta_{n}\right) \nabla f\left(T x_{n}\right)\right)$ for all $n \in \mathbb{N}$. Then

$$
x_{n+1}=\nabla f^{\prime \prime}\left(\alpha_{n} \nabla f(u)+\left(1-\alpha_{n}\right) \nabla f\left(y_{n}\right)\right)
$$

for all $n \in \mathbb{N}$. By using (2.5) and (2.2), we have

$$
\begin{aligned}
D_{f}\left(p, y_{n}\right) & =D_{f}\left(p, \nabla f^{*}\left(\beta_{n} \nabla f\left(x_{n}\right)+\left(1-\beta_{n}\right) \nabla f\left(T x_{n}\right)\right)\right) \\
& \leq \beta_{n} D_{f}\left(p, x_{n}\right)+\left(1-\beta_{n}\right) D_{f}\left(p, T x_{n}\right) \\
& \leq \beta_{n} D_{f}\left(p, x_{n}\right)+\left(1-\beta_{n}\right) D_{f}\left(p, x_{n}\right) \\
& =D_{f}\left(p, x_{n}\right)
\end{aligned}
$$

and

$$
\begin{aligned}
D_{f}\left(p, x_{n+1}\right) & =D_{f}\left(p, \nabla f^{*}\left(\alpha_{n} \nabla f(u)+\left(1-\alpha_{n}\right) \nabla f\left(y_{n}\right)\right)\right) \\
& \leq \alpha_{n} D_{f}(p, u)+\left(1-\alpha_{n}\right) D_{f}\left(p, y_{n}\right) \\
& \leq \alpha_{n} D_{f}(p, u)+\left(1-\alpha_{n}\right) D_{f}\left(p, x_{n}\right) \\
& \leq \max \left\{D_{f}(p, u), D_{f}\left(p, x_{n}\right)\right\} .
\end{aligned}
$$

By induction, we have

$$
D_{f}\left(p, x_{n+1}\right) \leq \max \left\{D_{f}(p, u), D_{f}\left(p, x_{1}\right)\right\}
$$

for all $n \in \mathbb{N}$. This implies that $\left\{D_{f}\left(p, x_{n}\right)\right\}$ is bounded, and hence $\left\{D_{f}\left(p, y_{n}\right)\right\}$ is bounded.

We next show that the sequence $\left\{x_{n}\right\}$ is also bounded. We follow the proof line as in [16]. Since $\left\{D_{f}\left(p, x_{n}\right)\right\}$ is bounded, there exists $M>0$ such that

$$
f(p)-\left\langle\nabla f\left(x_{n}\right), p\right\rangle+f^{*}\left(\nabla f\left(x_{n}\right)\right)=V_{f}\left(p, \nabla f\left(x_{n}\right)\right)=D_{f}\left(p, x_{n}\right) \leq M .
$$

Hence $\left\{\nabla f\left(x_{n}\right)\right\}$ is contained in the sublevel set $l e v_{\leq}^{\psi}(M-f(p))$, where $\psi=f^{\prime \prime}-\langle\cdot, p\rangle$. Since $f$ is lower semicontinuous, $f^{\prime \prime}$ is weak" lower semicontinuous. Hence the function $\psi$ is coercive by Moreau-Rockafellar theorem (see [40, Theorem 7A]). This shows that $\left\{\nabla f\left(x_{n}\right)\right\}$ is bounded. Since $f$ is strongly coercive, $f^{*}$ is bounded on bounded sets (see [23, Theorem 3.3]). Hence $\nabla f^{*}$ is also bounded on bounded subsets of $E^{*}$ (see [29, Proposition 1.1.11]). Since $f$ is a Legendre function, it follows that $x_{n}=\nabla f^{\prime \prime}\left(\nabla f\left(x_{n}\right)\right)$ is bounded for all $n \in \mathbb{N}$. Therefore $\left\{x_{n}\right\}$ is bounded. So are $\left\{y_{n}\right\},\left\{T x_{n}\right\},\left\{\nabla f\left(y_{n}\right)\right\}$ and $\left\{\nabla f\left(T x_{n}\right)\right\}$. Indeed, since $f$ is a bounded function defined on bounded subsets of $E, \nabla f$ is also bounded on bounded subsets of $E$ (see [29, Proposition 1.1.11]). Therefore $\left\{\nabla f\left(T x_{n}\right)\right\}$ is bounded.

We next show that if there exists a subsequence $\left\{x_{n_{k}}\right\}$ of $\left\{x_{n}\right\}$ such that

$$
\lim _{k \rightarrow \infty}\left(D_{f}\left(p, x_{n_{k}+1}\right)-D_{f}\left(p, x_{n_{k}}\right)\right)=0,
$$


then

$$
\lim _{k \rightarrow \infty}\left(D_{f}\left(p, T x_{n_{k}}\right)-D_{f}\left(p, x_{n_{k}}\right)\right)=0 .
$$

In fact, since $\left\{\nabla f\left(y_{n_{k}}\right)\right\}$ is bounded and $\alpha_{n_{k}} \rightarrow 0$, from (3.2) we have

$$
\lim _{k \rightarrow \infty}\left\|\nabla f\left(x_{n_{k}+1}\right)-\nabla f\left(y_{n_{k}}\right)\right\|=\lim _{k \rightarrow \infty} \alpha_{n_{k}}\left\|\nabla f(u)-\nabla f\left(y_{n_{k}}\right)\right\|=0 .
$$

Since $f$ is strongly coercive and uniformly convex on bounded subsets of $E, f^{*}$ is uniformly Fréchet differentiable on bounded subsets of $E^{*}$ (see [19, Proposition 3.6.2]). Since $f$ is Legendre, by Lemma 2.1, we have

$$
\lim _{k \rightarrow \infty}\left\|x_{n_{k}+1}-y_{n_{k}}\right\|=\lim _{k \rightarrow \infty}\left\|\nabla f^{*}\left(\nabla f\left(x_{n_{k}+1}\right)\right)-\nabla f^{*}\left(\nabla f\left(y_{n_{k}}\right)\right)\right\|=0 .
$$

On the other hand, since $f$ is uniformly Fréchet differentiable on bounded subsets of $E, f$ is uniformly continuous on bounded subsets of $E$ (see [41, Theorem 1.8]). It follows that

$$
\lim _{k \rightarrow \infty}\left|f\left(x_{n_{k}+1}\right)-f\left(y_{n_{k}}\right)\right|=0 .
$$

We now consider the following equality.

$$
\begin{aligned}
D_{f}\left(p, y_{n_{k}}\right)-D_{f}\left(p, x_{n_{k}}\right) \\
=f(p)-f\left(y_{n_{k}}\right)-\left\langle\nabla f\left(y_{n_{k}}\right), p-y_{n_{k}}\right\rangle-D_{f}\left(p, x_{n_{k}}\right) \\
=f(p)-f\left(x_{n_{k}+1}\right)+f\left(x_{n_{k}+1}\right)-f\left(y_{n_{k}}\right)-\left\langle\nabla f\left(x_{n_{k}+1}\right), p-x_{n_{k}+1}\right\rangle \\
\quad+\left\langle\nabla f\left(x_{n_{k}+1}\right), p-x_{n_{k}+1}\right\rangle-\left\langle\nabla f\left(y_{n_{k}}\right), p-y_{n_{k}}\right\rangle-D_{f}\left(p, x_{n_{k}}\right) \\
=D_{f}\left(p, x_{n_{k}+1}\right)+\left(f\left(x_{n_{k}+1}\right)-f\left(y_{n_{k}}\right)\right)+\left\langle\nabla f\left(x_{n_{k}+1}\right), p-x_{n_{k}+1}\right\rangle \\
\quad-\left\langle\nabla f\left(y_{n_{k}}\right), p-y_{n_{k}}\right\rangle-D_{f}\left(p, x_{n_{k}}\right) \\
=\left(D_{f}\left(p, x_{n_{k}+1}\right)-D_{f}\left(p, x_{n_{k}}\right)\right)+\left(f\left(x_{n_{k}+1}\right)-f\left(y_{n_{k}}\right)\right) \\
\quad+\left\langle\nabla f\left(x_{n_{k}+1}\right)-\nabla f\left(y_{n_{k}}\right), p-x_{n_{k}+1}\right\rangle-\left\langle\nabla f\left(y_{n_{k}}\right), x_{n_{k}+1}-y_{n_{k}}\right\rangle .
\end{aligned}
$$

It follows from (3.4)-(3.6) that

$$
\lim _{k \rightarrow \infty}\left(D_{f}\left(p, y_{n_{k}}\right)-D_{f}\left(p, x_{n_{k}}\right)\right)=0
$$

and

$$
\begin{aligned}
D_{f}\left(p, y_{n_{k}}\right)-D_{f}\left(p, x_{n_{k}}\right) & \leq \beta_{n_{k}} D_{f}\left(p, x_{n_{k}}\right)+\left(1-\beta_{n_{k}}\right) D_{f}\left(p, T x_{n_{k}}\right)-D_{f}\left(p, x_{n_{k}}\right) \\
& =\left(1-\beta_{n_{k}}\right)\left(D_{f}\left(p, T x_{n_{k}}\right)-D_{f}\left(p, x_{n_{k}}\right)\right) .
\end{aligned}
$$

By virtue of condition (C3), (2.2) and (3.8), we have

$$
\lim _{k \rightarrow \infty}\left(D_{f}\left(p, T x_{n_{k}}\right)-D f\left(p, x_{n_{k}}\right)\right)=0 .
$$


We next consider the following two cases.

Case 1. $D_{f}\left(p, x_{n+1}\right) \leq D_{f}\left(p, x_{n}\right)$ for all sufficiently large $n$. Hence the sequence $\left\{D_{f}\left(p, x_{n}\right)\right\}$ is bounded and nonincreasing. So, the $\operatorname{limit}_{n \rightarrow \infty} D_{f}\left(p, x_{n}\right)$ exists. This shows that $\lim _{n \rightarrow \infty}\left(D_{f}\left(p, x_{n+1}\right)-D_{f}\left(p, x_{n}\right)\right)=0$, and hence

$$
\lim _{n \rightarrow \infty}\left(D_{f}\left(p, T x_{n}\right)-D_{f}\left(p, x_{n}\right)\right)=0 .
$$

Since $T$ is Bregman strongly nonexpansive, we have

$$
\lim _{n \rightarrow \infty} D_{f}\left(x_{n}, T x_{n}\right)=0
$$

Since $f$ is totally convex on bounded subsets of $E$, by Lemma 2.6, we have

$$
\lim _{n \rightarrow \infty}\left\|x_{n}-T x_{n}\right\|=0
$$

From (2.5) we have

$$
\begin{aligned}
D_{f}\left(T x_{n}, y_{n}\right) & =D_{f}\left(T x_{n}, \nabla f^{*}\left(\beta_{n} \nabla f\left(x_{n}\right)+\left(1-\beta_{n}\right) \nabla f\left(T x_{n}\right)\right)\right) \\
& \leq \beta_{n} D_{f}\left(T x_{n}, x_{n}\right)+\left(1-\beta_{n}\right) D_{f}\left(T x_{n}, T x_{n}\right) \\
& =\beta_{n} D_{f}\left(T x_{n}, x_{n}\right) \rightarrow 0
\end{aligned}
$$

and

$$
D_{f}\left(y_{n}, x_{n+1}\right) \leq \alpha_{n} D_{f}\left(y_{n}, u\right)+\left(1-\alpha_{n}\right) D_{f}\left(y_{n}, y_{n}\right)=\alpha_{n} D_{f}\left(y_{n}, u\right) \rightarrow 0 .
$$

From (3.11), (3.12) and Lemma 2.6, we get

$$
\lim _{n \rightarrow \infty}\left\|T x_{n}-y_{n}\right\|=0 \quad \text { and } \quad \lim _{n \rightarrow \infty}\left\|y_{n}-x_{n+1}\right\|=0
$$

From (3.10), (3.13) and invoking Lemma 3.1, we have

$$
\lim _{n \rightarrow \infty} \sup \left\langle\nabla f(u)-\nabla f(p), x_{n+1}-p\right\rangle=\lim _{n \rightarrow \infty} \sup \left\langle\nabla f(u)-\nabla f(p), x_{n}-p\right\rangle \leq 0 .
$$

Finally, we show that $x_{n} \rightarrow p$. In fact, by using (2.4), we obtain that

$$
\begin{aligned}
D_{f}\left(p, x_{n+1}\right)= & D_{f}\left(p, \nabla f^{*}\left(\alpha_{n} \nabla f(u)+\left(1-\alpha_{n}\right) \nabla f\left(y_{n}\right)\right)\right) \\
= & V_{f}\left(p, \alpha_{n} \nabla f(u)+\left(1-\alpha_{n}\right) \nabla f\left(y_{n}\right)\right) \\
\leq & V_{f}\left(p, \alpha_{n} \nabla f(u)+\left(1-\alpha_{n}\right) \nabla f\left(y_{n}\right)-\alpha_{n}(\nabla f(u)-\nabla f(p))\right) \\
& +\left\langle\alpha_{n}(\nabla f(u)-\nabla f(p)), \nabla f^{\prime \prime}\left(\alpha_{n} \nabla f(u)+\left(1-\alpha_{n}\right) \nabla f\left(y_{n}\right)\right)-p\right\rangle \\
= & V_{f}\left(p, \alpha_{n} \nabla f(p)+\left(1-\alpha_{n}\right) \nabla f\left(y_{n}\right)\right)+\alpha_{n}\left\langle\nabla f(u)-\nabla f(p), x_{n+1}-p\right\rangle \\
= & D_{f}\left(p, \nabla f^{*}\left(\alpha_{n} \nabla f(p)+\left(1-\alpha_{n}\right) \nabla f\left(y_{n}\right)\right)\right)+\alpha_{n}\left\langle\nabla f(u)-\nabla f(p), x_{n+1}-p\right\rangle \\
\leq & \alpha_{n} D_{f}(p, p)+\left(1-\alpha_{n}\right) D_{f}\left(p, y_{n}\right)+\alpha_{n}\left\langle\nabla f(u)-\nabla f(p), x_{n+1}-p\right\rangle \\
\leq & \left(1-\alpha_{n}\right) D_{f}\left(p, x_{n}\right)+\alpha_{n}\left\langle\nabla f(u)-\nabla f(p), x_{n+1}-p\right\rangle .
\end{aligned}
$$


By Lemma 2.9, we can conclude that $\lim _{n \rightarrow \infty} D_{f}\left(p, x_{n}\right)=0$. Therefore, by Lemma $2.6, x_{n} \rightarrow$ $p$ since $f$ is totally convex on bounded subsets of $E$.

Case 2. Suppose that there exists a subsequence $\left\{D_{f}\left(p, n_{i}\right)\right\}$ of $\left\{D_{f}\left(p, x_{n}\right)\right\}$ such that

$$
D_{f}\left(p, x_{n_{i}}\right)<D_{f}\left(p, x_{n_{i}+1}\right)
$$

for all $i \in \mathbb{N}$. Then, by Lemma 2.10 , there exists a nondecreasing sequence $\left\{m_{k}\right\} \subset \mathbb{N}$ such that $m_{k} \rightarrow \infty$

$$
D_{f}\left(p, x_{m_{k}}\right) \leq D_{f}\left(p, x_{m_{k}+1}\right) \quad \text { and } \quad D_{f}\left(p, x_{k}\right) \leq D_{f}\left(p, x_{m_{k}+1}\right)
$$

for all $k \in \mathbb{N}$. So, we have

$$
\begin{aligned}
0 & \leq \lim _{k \rightarrow \infty}\left(D_{f}\left(p, x_{m_{k}+1}\right)-D_{f}\left(p, x_{m_{k}}\right)\right) \\
& \leq \limsup _{n \rightarrow \infty}\left(D_{f}\left(p, x_{n+1}\right)-D_{f}\left(p, x_{n}\right)\right) \\
& \leq \limsup _{n \rightarrow \infty}\left(\alpha_{n} D_{f}(p, u)+\left(1-\alpha_{n}\right) D_{f}\left(p, y_{n}\right)-D_{f}\left(p, x_{n}\right)\right) \\
& \leq \limsup _{n \rightarrow \infty}\left(\alpha_{n} D_{f}(p, u)+\left(1-\alpha_{n}\right)\left(\beta_{n} D_{f}\left(p, x_{n}\right)+\left(1-\beta_{n}\right) D_{f}\left(p, T x_{n}\right)\right)-D_{f}\left(p, x_{n}\right)\right) \\
& =\limsup _{n \rightarrow \infty}\left(\alpha_{n} D_{f}(p, u)+\left(1-\alpha_{n}\right)\left(1-\beta_{n}\right)\left(D_{f}\left(p, T x_{n}\right)\right)-D_{f}\left(p, x_{n}\right)\right)-\alpha_{n}\left(D_{f}\left(p, x_{n}\right)\right) \\
& \leq \limsup _{n \rightarrow \infty} \alpha_{n}\left(D_{f}(p, u)-D_{f}\left(p, x_{n}\right)\right)=0
\end{aligned}
$$

This implies

$$
\lim _{k \rightarrow \infty}\left(D_{f}\left(p, x_{m_{k}+1}\right)-D_{f}\left(p, x_{m_{k}}\right)\right)=0
$$

Following the proof line in Case 1, we can verify

$$
\lim _{k \rightarrow \infty}\left\langle\nabla f(u)-\nabla f(p), x_{m_{k}+1}-p\right\rangle \leq 0
$$

and

$$
D_{f}\left(p, x_{m_{k}+1}\right) \leq\left(1-\alpha_{m_{k}}\right) D_{f}\left(p, x_{m_{k}}\right)+\alpha_{m_{k}}\left\langle\nabla f(u)-f(p), x_{m_{k}+1}-p\right\rangle .
$$

Since $D_{f}\left(p, x_{m_{k}}\right) \leq D_{f}\left(p, x_{m_{k}+1}\right)$, we have

$$
\begin{aligned}
\alpha_{m_{k}} D_{f}\left(p, x_{m_{k}}\right) & \leq D_{f}\left(p, x_{m_{k}}\right)-D_{f}\left(p, x_{m_{k}+1}\right)+\alpha_{m_{k}}\left\langle\nabla f(u)-\nabla f(p), x_{m_{k}+1}-p\right\rangle \\
& \leq \alpha_{m_{k}}\left\langle\nabla f(u)-\nabla f(p), x_{m_{k}+1}-p\right\rangle .
\end{aligned}
$$

In particular, since $\alpha_{m_{k}}>0$, we get

$$
D_{f}\left(p, x_{m_{k}}\right) \leq\left\langle\nabla f(u)-\nabla f(p), x_{m_{k}+1}-p\right\rangle .
$$


Hence it follows from (3.18) that $\lim _{k \rightarrow \infty} D_{f}\left(p, x_{m_{k}}\right)=0$. Using this and (3.17) together, we conclude that

$$
\lim _{k \rightarrow \infty} \sup D_{f}\left(p, x_{k}\right) \leq \lim _{k \rightarrow \infty} D_{f}\left(p, x_{m_{k}+1}\right)=0
$$

This completes the proof.

Letting $\beta_{n} \equiv \beta$ gives the following result.

Corollary 3.3 Let $E$ be a real reflexive Banach space $E$, and let $f: E \rightarrow \mathbb{R}$ be a strongly coercive Legendre function which is bounded, uniformly Fréchet differentiable and totally convex on bounded subsets of $E$. Let $T$ be a Bregman strongly nonexpansive mapping on $E$ such that $F(T)=\hat{F}(T) \neq \emptyset$. Suppose that $u \in E$ and define the sequence $\left\{x_{n}\right\}$ as follows: $x_{1} \in E$ and

$$
x_{n+1}=\nabla f^{*}\left(\alpha_{n} \nabla f(u)+\left(1-\alpha_{n}\right)\left(\beta \nabla f\left(x_{n}\right)+(1-\beta) \nabla f\left(T x_{n}\right)\right)\right)
$$

for all $n \in \mathbb{N}$, where $\left\{\alpha_{n}\right\}$ is a sequence in $(0,1)$ satisfying conditions $(\mathrm{C} 1)$ and $(\mathrm{C} 2)$, and $\beta \in(0,1)$. Then $\left\{x_{n}\right\}$ converges strongly to $P_{F(T)}^{f}(u)$.

\section{Application to a zero point problem of maximal monotone mappings and equilibrium problems}

Let $E$ be a real reflexive Banach space. Let $A: E \rightarrow 2^{E^{\prime \prime}}$ be a set-valued mapping. The domain of $A$ is denoted by $\operatorname{dom} A=\{x \in E: A x \neq \emptyset\}$, and also the graph of $A$ is denoted by $G(A)=\left\{\left(x, x^{*}\right) \in E \times E^{*}: x^{*} \in A x\right\} . A$ is said to be monotone if $\left\langle x-y, x^{*}-y^{*}\right\rangle \geq 0$ for each $\left(x, x^{*}\right),\left(y, y^{*}\right) \in G(A)$. It is said to be maximal monotone if its graph is not contained in the graph of any other monotone operator on $E$. It is known that if $A$ is maximal monotone, then the set $A^{-1}\left(0^{*}\right)=\left\{z \in E: 0^{\prime \prime} \in A z\right\}$ is closed and convex. Now, we apply Theorem 3.2 to the problem of finding $x \in E$ such that $0^{*} \in A x$, which strongly relates to the convex minimization problems in optimization, economics and applied sciences.

The resolvent of $A$, denoted by $\operatorname{Res}_{A}^{f}: E \rightarrow 2^{E}$, is defined as follows [13]:

$$
\operatorname{Res}_{A}^{f}(x)=(\nabla f+A)^{-1} \circ \nabla f(x) .
$$

It is known that $F\left(\operatorname{Res}_{A}^{f}\right)=A^{-1}\left(0^{*}\right)$, and $\operatorname{Res}_{A}^{f}$ is single-valued and Bregman firmly nonexpansive (see [13]). If $f$ is a Legendre function which is bounded, uniformly Fréchet differentiable on bounded subsets of $E$, then $\hat{F}\left(\operatorname{Res}_{A}^{f}\right)=F\left(\operatorname{Res}_{A}^{f}\right)$ (see [16]). The Yosida approximation $A_{\lambda}: E \rightarrow E, \lambda>0$, is also defined by

$$
A_{\lambda}(x)=\frac{1}{\lambda}\left(\nabla f(x)-\nabla f\left(\operatorname{Res}_{\lambda A}^{f}(x)\right)\right)
$$

for all $x \in E$. From Proposition 2.7 in [42], we know that $\left(\operatorname{Res}_{\lambda A}^{f}(x), A_{\lambda}(x)\right) \in G(A)$ and $0^{\prime \prime} \in$ $A x$ if and only if $0^{*} \in A_{\lambda} x$ for all $x \in E$ and $\lambda>0$. Using these facts, we obtain the following result by replacing $T=\operatorname{Res}_{\lambda A}^{f}, \lambda>0$ in Theorem 3.2. 
Theorem 4.1 Let $C$ be a nonempty, closed and convex subset of a real reflexive Banach space $E$, and let $f: E \rightarrow \mathbb{R}$ be a strongly coercive Legendre function which is bounded, uniformly Fréchet differentiable and totally convex on bounded subsets of E. Let $A: E \rightarrow 2^{E^{2}}$ be a maximal monotone operator such that $A^{-1}\left(0^{*}\right) \neq \emptyset$. Suppose that $u \in E$ and define the sequence $\left\{x_{n}\right\}$ as follows: $x_{1} \in E$ and

$$
x_{n+1}=\nabla f^{*}\left(\alpha_{n} \nabla f(u)+\left(1-\alpha_{n}\right)\left(\beta_{n} \nabla f\left(x_{n}\right)+\left(1-\beta_{n}\right) \nabla f\left(\operatorname{Res}_{\lambda A}^{f} x_{n}\right)\right)\right), \quad \forall n \geq 1,
$$

where $\lambda>0$ and $\left\{\alpha_{n}\right\}$ and $\left\{\beta_{n}\right\}$ are sequences in $(0,1)$ satisfying

(C1) $\lim _{n \rightarrow \infty} \alpha_{n}=0$;

(C2) $\sum_{n=1}^{\infty} \alpha_{n}=\infty$;

(C3) $0<\liminf _{n \rightarrow \infty} \beta_{n} \leq \lim \sup _{n \rightarrow \infty} \beta_{n}<1$.

Then $\left\{x_{n}\right\}$ converges strongly to $P_{A^{-1}\left(0^{*}\right)}^{f}(u)$, where $P_{A^{-1}\left(0^{\circ}\right)}^{f}$ is the Bregman projection of $E$ onto $A^{-1}\left(0^{*}\right)$.

Let $C$ be a nonempty, closed and convex subset of $E$, and let $\Theta: C \times C \rightarrow \mathbb{R}$ be a bifunction. Now, we apply Theorem 3.2 to the problem of finding $x \in C$ such that $\Theta(x, y) \geq 0$ for all $y \in C$. Such a problem is called an equilibrium problem and the solutions set is denoted by $\operatorname{EP}(\Theta)$. Numerous problems in economics, physics and applied sciences can be reduced to finding solutions of equilibrium problems.

In order to solve the equilibrium problem, let us assume that a bifunction $\Theta: C \times C \rightarrow \mathbb{R}$ satisfies the following conditions [43]:

$\left(\mathrm{A}_{1}\right) \Theta(x, x)=0, \forall x \in C$.

$\left(\mathrm{A}_{2}\right) \Theta$ is monotone, i.e., $\Theta(x, y)+\Theta(y, x) \leq 0, \forall x, y \in C$.

$\left(\mathrm{A}_{3}\right) \lim \sup _{t \downarrow 0} \Theta(x+t(z-x), y) \leq \Theta(x, y), \forall x, z, y \in C$.

$\left(\mathrm{A}_{4}\right)$ The function $y \mapsto \Theta(x, y)$ is convex and lower semi-continuous.

The resolvent of a bifunction $\Theta[44]$ is the operator $\operatorname{Res}_{\Theta}^{f}: E \rightarrow 2^{C}$ defined by

$$
\operatorname{Res}_{\Theta}^{f}(x)=\{z \in C: \Theta(z, y)+\langle\nabla f(z)-\nabla f(x), y-z\rangle \geq 0, \forall y \in C\} .
$$

From Lemma 1 in [15], if $f: E \rightarrow(-\infty,+\infty]$ is a strongly coercive and Gâteaux differentiable function, and $\Theta$ satisfies conditions $\left(\mathrm{A}_{1}\right)-\left(\mathrm{A}_{4}\right)$, then $\operatorname{dom}\left(\operatorname{Res}_{\Theta}^{f}\right)=E$.

The following lemma gives us some characterizations of the resolvent $\operatorname{Res}_{\Theta}^{f}$.

Lemma 4.2 [15] Let $E$ be a real reflexive Banach space, and let $C$ be a nonempty closed convex subset of $E$. Let $f: E \rightarrow(-\infty,+\infty]$ be a Legendre function. If the bifunction $\Theta$ : $C \times C \rightarrow \mathbb{R}$ satisfies the conditions $\left(\mathrm{A}_{1}\right)-\left(\mathrm{A}_{4}\right)$. Then the following hold:

(i) $\operatorname{Res}_{\Theta}^{f}$ is single-valued;

(ii) $\operatorname{Res}_{\Theta}^{f}$ is a Bregman firmly nonexpansive operator;

(iii) $F\left(\operatorname{Res}_{\Theta}^{f}\right)=\mathrm{EP}(\Theta)$;

(iv) $\mathrm{EP}(\Theta)$ is a closed and convex subset of $C$;

(v) for all $x \in E$ and for all $p \in F\left(\operatorname{Res}_{\Theta}^{f}\right)$, we have

$$
D_{f}\left(p, \operatorname{Res}_{\Theta}^{f}(x)\right)+D_{f}\left(\operatorname{Res}_{\Theta}^{f}(x), x\right) \leq D_{f}(p, x) .
$$


In addition, by Reich and Sabach [16], if $f$ is uniformly Fréchet differentiable and bounded on bounded subsets of $E$, then we have from Lemma 4.2 that $F\left(\operatorname{Res}_{\Theta}^{f}\right)=\hat{F}\left(\operatorname{Res}_{\Theta}^{f}\right)=$ $\operatorname{EP}(\Theta)$ is closed and convex. Also, by replacing $T=\operatorname{Res}_{\Theta}^{f}$ in Theorem 3.2, we obtain the following result.

Theorem 4.3 Let $C$ be a nonempty, closed and convex subset of a real reflexive Banach space $E$, and let $f: E \rightarrow \mathbb{R}$ be a strongly coercive Legendre function which is bounded, uniformly Fréchet differentiable and totally convex on bounded subsets of $E$. Let $\Theta: C \times C \rightarrow \mathbb{R}$ be a bifunction which satisfies the conditions $\left(\mathrm{A}_{1}\right)-\left(\mathrm{A}_{4}\right)$ such that $\mathrm{EP}(\Theta) \neq \emptyset$. Suppose that $u \in E$ and define the sequence $\left\{x_{n}\right\}$ as follows: $x_{1} \in E$ and

$$
x_{n+1}=\nabla f^{\prime \prime}\left(\alpha_{n} \nabla f(u)+\left(1-\alpha_{n}\right)\left(\beta_{n} \nabla f\left(x_{n}\right)+\left(1-\beta_{n}\right) \nabla f\left(\operatorname{Res}_{\Theta}^{f} x_{n}\right)\right)\right), \quad \forall n \geq 1,
$$

where $\left\{\alpha_{n}\right\}$ and $\left\{\beta_{n}\right\}$ are sequences in $(0,1)$ satisfying

(C1) $\lim _{n \rightarrow \infty} \alpha_{n}=0$;

(C2) $\sum_{n=1}^{\infty} \alpha_{n}=\infty$;

(C3) $0<\liminf _{n \rightarrow \infty} \beta_{n} \leq \lim \sup _{n \rightarrow \infty} \beta_{n}<1$.

Then $\left\{x_{n}\right\}$ converges strongly to $P_{\mathrm{EP}(\Theta)}^{f}(u)$, where $P_{\mathrm{EP}(\Theta)}^{f}$ is the Bregman projection of $E$ onto $\mathrm{EP}(\Theta)$.

Competing interests
The authors declare that they have no competing interests.

Authors' contributions

All authors read and approved the final manuscript.

\section{Author details}

${ }^{1}$ Institute of Mathematics, Yibin University, Yibin, Sichuan 644007, P.R. China. ${ }^{2}$ College of Statistics and Mathematics, Yunnan University of Finance and Economics, Kunming, Yunnan 650221, China.

\section{Acknowledgements}

The authors would like to express their thanks to the referees for their helpful comments and suggestions. This work was supported by the Scientific Research Fund of Sichuan Provincial Education Department (12ZA295), the Scientific Research Fund of Science Technology Department of Sichuan Province (2011JYZ011) and the Natural Science foundation of Yibin university (2011Z08).

Received: 4 November 2012 Accepted: 5 March 2013 Published: 2 April 2013

\section{References}

1. Mann, WR: Mean value methods in iteration. Proc. Am. Math. Soc. 4, 506-510 (1953)

2. Genel, A, Lindenstrauss, J: An example concerning fixed points. Isr. J. Math. 22, 957-962 (1975)

3. Halpern, B: Fixed points of nonexpanding maps. Bull. Am. Math. Soc. 73, 957-961 (1967)

4. Lions, PL: Approximation de points fixes de contractions. C. R. Math. Acad. Sci. Paris, Sér. A-B 284, A1357-A1359 (1977)

5. Reich, S: Approximating fixed points of nonexpansive mappings. Panam. Math. J. 4, 23-28 (1994)

6. Wittmann, R: Approximation of fixed points of nonexpansive mappings. Arch. Math. 58, 486-491 (1992)

7. Shioji, N, Takahashi, W: Strong convergence of approximated sequences for nonexpansive mapping in Banach spaces. Proc. Am. Math. Soc. 125, 3641-3645 (1997)

8. Xu, HK: Another control condition in an iterative method for nonexpansive mappings. Bull. Aust. Math. Soc. 65, 109-113 (2002)

9. Cho, YJ, Kang, SM, Zhou, H: Some control conditions on iterative methods. Commun. Appl. Nonlinear Anal. 12, 27-34 (2005)

10. Chidume, CE, Chidume, CO: Iterative approximation of fixed points of nonexpansive mappings. J. Math. Anal. Appl. 318, 288-295 (2006)

11. Suzuki, T: A sufficient and necessary condition for Halpern-type strong convergence to fixed points of nonexpansive mappings. Proc. Am. Math. Soc. 135, 99-106 (2007)

12. Saejung, S: Halpern's iteration in Banach spaces. Nonlinear Anal. TMA 73, 3431-3439 (2010)

13. Bauschke, $\mathrm{HH}$, Borwein, JM, Combettes, PL: Bregman monotone optimization algorithms. SIAM J. Control Optim. 42 596-636 (2003) 
14. Butnariu, D, Kassay, G: A proximal-projection method for finding zeroes of set-valued operators. SIAM J. Control Optim. 47, 2096-2136 (2008)

15. Reich, S, Sabach, S: Two strong convergence theorems for Bregman strongly nonexpansive operators in reflexive Banach spaces. Nonlinear Anal. TMA 73, 122-135 (2010)

16. Reich, S, Sabach, S: Existence and approximation of fixed points of Bregman firmly nonexpansive mappings in reflexive Banach spaces. In: Fixed-Point Algorithms for Inverse Problems in Science and Engineering, pp. 301-316. Springer, New York (2011)

17. Rockafellar, RT: Convex Analysis. Princeton University Press, Princeton (1970)

18. Hiriart-Urruty, J-B, Lemaréchal, C: Convex Analysis and Minimization Algorithms II. Grundlehren der mathematischen Wissenschaften, vol. 306. Springer, Berlin (1993)

19. Zălinescu, C: Convex Analysis in General Vector Spaces. World Scientific, River Edge (2002)

20. Asplund, E, Rockafellar, RT: Gradients of convex functions. Trans. Am. Math. Soc. 139, 443-467 (1969)

21. Bonnans, JF, Shapiro, A: Perturbation Analysis of Optimization Problems. Springer, New York (2000)

22. Reich, S, Sabach, S: A strong convergence theorem for a proximal-type algorithm in reflexive Banach spaces. J. Nonlinear Convex Anal. 10,471-485 (2009)

23. Bauschke, HH, Borwein, JM, Combettes, PL: Essential smoothness, essential strict convexity, and Legendre functions in Banach spaces. Commun. Contemp. Math. 3, 615-647 (2001)

24. Bauschke, $\mathrm{HH}$, Borwein, JM: Legendre functions and the method of random Bregman projections. J. Convex Anal. 4, 27-67 (1997)

25. Censor, Y, Lent, A: An iterative row-action method for interval convex programming. J. Optim. Theory Appl. 34, 321-353 (1981)

26. Bregman, LM: The relaxation method for finding the common point of convex sets and its application to the solution of problems in convex programming. U.S.S.R. Comput. Math. Math. Phys. 7, 200-217 (1967)

27. Butnariu, D, Resmerita, E: Bregman distances, totally convex functions and a method for solving operator equations in Banach spaces. Abstr. Appl. Anal. 2006, Article ID 84919 (2006)

28. Resmerita, E: On total convexity, Bregman projections and stability in Banach spaces. J. Convex Anal. 11, 1-16 (2004)

29. Butnariu, D, lusem, AN: Totally Convex Functions for Fixed Points Computation and Infinite Dimensional Optimization. Kluwer Academic, Dordrecht (2000)

30. Censor, Y, Reich, S: Iterations of paracontractions and firmly nonexpansive operators with applications to feasibility and optimization. Optimization 37, 323-339 (1996)

31. Reich, S: A weak convergence theorem for the alternating method with Bregman distances. In: Theory and Applications of Nonlinear Operators of Accretive and Monotone Type, pp. 313-318. Dekker, New York (1996)

32. Bruck, RE, Reich, S: Nonexpansive projections and resolvents of accretive operators in Banach spaces. Houst. J. Math. 3, 459-470 (1977)

33. Kohsaka, F, Takahashi, W: Existence and approximation of fixed points of firmly nonexpansive-type mappings in Banach spaces. SIAM J. Control Optim. 19, 824-835 (2008)

34. Alber, Yl: Metric and generalized projection operators in Banach spaces: properties and applications. In: Kartsatos, AG (ed.) Theory and Applications of Nonlinear Operator of Accretive and Monotone Type, pp. 15-50. Dekker, New York (1996)

35. Kohsaka, F, Takahashi, W: Proximal point algorithms with Bregman functions in Banach spaces. J. Nonlinear Convex Anal. 6, 505-523 (2005)

36. Phelps, RP: Convex Functions, Monotone Operators, and Differentiability, 2nd edn. Lecture Notes in Mathematics, vol. 1364. Springer, Berlin (1993)

37. Xu, HK: Another control condition in an iterative method for nonexpansive mappings. Bull. Aust. Math. Soc. 65 109-113 (2002)

38. Mainge, PE: Strong convergence of projected subgradient methods for nonsmooth and nonstrictly convex minimization. Set-Valued Anal. 16, 899-912 (2008)

39. Suantai, S, Cho, YJ, Cholamjiak, P: Halpern's iteration for Bregman strongly nonexpansive mappings in reflexive Banach spaces. Comput. Math. Appl. 64, 489-499 (2012)

40. Rockafellar, RT: Level sets and continuity of conjugate convex functions. Trans. Am. Math. Soc. 123, 46-63 (1966)

41. Ambrosetti, A, Prodi, G: A Primer of Nonlinear Analysis. Cambridge University Press, Cambridge (1993)

42. Reich, S, Sabach, S: Two strong convergence theorems for a proximal method in reflexive Banach spaces. Numer. Funct. Anal. Optim. 31, 22-44 (2010)

43. Blum, E, Oettli, W: From optimization and variational inequalities to equilibrium problems. Math. Stud. 63, 123-145 (1994)

44. Combettes, PL, Hirstoaga, SA: Equilibrium programming in Hilbert spaces. J. Nonlinear Convex Anal. 6, 117-136 (2005)

doi:10.1186/1029-242X-2013-146

Cite this article as: Zhu and Chang: Halpern-Mann's iterations for Bregman strongly nonexpansive mappings in

reflexive Banach spaces with applications. Journal of Inequalities and Applications 2013 2013:146. 